\title{
Prosocial Behavior and Religion: New Evidence Based on Projective Measures and Peer Ratings
}

\author{
VASSILIS SAROGLOU \\ ISABELLE PICHON \\ LAURENCE TROMPETTE \\ MARIJKE VERSCHUEREN \\ REBECCA DERNELLE
}

\begin{abstract}
An important discrepancy seems to exist between self-reports and laboratory studies regarding prosociality among religious people. Some have even suggested that this involves moral hypocrisy on the part of religious people. However, the assumption of the four studies reported here is that the impact of religiousness on prosociality is limited but exists, and does not reflect self-delusion. In Study $1(N=106)$, religious young adults tended not to use indirect aggression in dealing with hypothetical daily hassles. In Study $2(N=105)$, female students' religiosity was associated with willingness to help close targets in hypothetical situations but the effect was not extended to unknown targets. In Studies $3(N=315,105$ triads) and $4(N=274,109$ targets $)$, religious targets not only reported high altruistic behavior and empathy, but were also perceived as such by peers (friends, siblings, or colleagues) in three out of four cases. Other results from the studies suggested that the prosociality of religious people is not an artifact of gender, social desirability bias, security in attachment, empathy, or honesty.
\end{abstract}

\section{INTRODUCTION}

Almost all psychological theories of religion assume that religion contributes to prosociality. Religion, as part of culture, provides mechanisms that control the natural destructiveness of humans caused by their narcissism and sexual impulses (Freud [1927] 1961). Freud saw God as a projection of the superegotic instance of the imaginary father and as such reminds people of the two important taboos of incest and killing (Freud [1913] 1919). Generativity, as the main developmental task of middle adulthood (Erikson 1963), is particularly emphasized within a religious perspective (McFadden 1999). Saints and holy figures are models of charity and altruism, i.e., behaviors that are pragmatically risky but important for the human community (James [1902] 1985). Religion provides specific reinforcements and punishments, thus solidifying social moral standards (Skinner 1969). From a sociobiological and evolutionary perspective, religion is assumed to allow for a shift from altruism limited to natural kinships toward a cultural altruism extended to larger cultural "kinships" (Batson 1983) and for the creation of broad coalitions promoting ties of extended reciprocal altruism (Kirkpatrick 1999b).

In line with the above theories, it is usually found that religious people tend to be-at least perceive themselves as-prosocial and helpful (see Batson, Schoenrade, and Ventis 1993, for

Vassilis Saroglou is an Associate Professor of Psychology and Director of the Centre for Psychology of Religion at the Department of Psychology, Division of Social Psychology, Université catholique de Louvain, Place du Cardinal Mercier 10,B 1348, Louvain-la-Neuve, Belgium.E-mail:Vassilis.Saroglou@psp.ucl.ac.be

Isabelle Pichon is a doctoral student in psychology at the Department of Psychology, Université catholique de Louvain. E-mail: Isabelle.Pichon@psp.ucl.ac.be

Laurence Trompette holds a master's degree in psychology from the Université catholique de Louvain. E-mail: laurencetrompette@hotmail.com

Marijke Verschueren holds a master's degree in psychology from the Katholieke Universiteit Leuven. E-mail: marijkeverschueren@skynet.be

Rebecca Dernelle holds a master's degree in psychology from the Université catholique de Louvain. E-mail: bbk220@yahoo.fr 
a review), agreeable (see Saroglou 2002a, in press, for meta-analyses), ready to forgive (see, e.g., McCullough and Worthington 1999, for a review), and valuing benevolence (see Saroglou, Delpierre, and Dernelle 2004, for a meta-analysis). Substantial evidence based on self-reports suggests in addition that the prosocial character of religious people in terms, for instance, of personality traits and values, although modest, demonstrates cross-cohort, cross-cultural, and cross-religious stability (Saroglou in press; Saroglou, Delpierre, and Dernelle 2004).

In contrast, when one turns to quasi-experimental social psychological studies, the dominant conclusion in psychology of religion today (Spilka et al. 2003) is that (intrinsically) religious people only appear to be helpful and prosocial: they are preoccupied with their positive selfperception rather than by the needs of others (Batson, Schoenrade, and Ventis 1993). More recent studies that investigated this question within the context of intergroup relations (prosocial tendencies of religious people toward targets that appear as threatening their values) lead to the conclusion that intrinsically religious people (Batson et al. 1999), religious fundamentalists (Jackson and Esses 1997), and even people high in quest religiosity (Batson et al. 2001; Goldfried and Miner 2002) are not willing to act prosocially and help targets perceived as representing outgroups; they are even rather discriminative toward them.

The overall impression one gets is that a considerable discrepancy exists between theories (all theories) and a large series of empirical studies based on self-reports, on the one hand, and quasiexperimental studies, on the other. A similar discrepancy between theories or self-reports and other measure-based studies seems to be the case regarding the impact of religion on forgiveness (McCullough and Worthington 1999). A logical conclusion seems to be that religious people may be moral hypocrites rather than altruists: they perceive themselves as altruists but their behavior does not confirm such a perception. Batson, Schoenrade, and Ventis (1993), for instance, explicitly advance hypocrisy when referring to studies on religion and prejudice. A second conclusion could be that all classic theorists in psychology of religion were wrong, basing themselves perhaps on a too optimistic and pragmatist view of religion as a social good.

We think, however, that drawing such conclusions is premature and perhaps inappropriate. First, Batson's research program focuses mainly on the altruistic versus egoistic motivation of religious people's prosociality. However, the nonaltruistic (thus, egoistic) motivation of prosociality is, in fact, an - at least partially - independent question from the one concerning the presence, conditions, scope, and limitations of this prosociality. Consequently, the question of whether religious people are moral hypocrites when they provide self-reports on prosociality cannot be answered only on the basis of the type of corresponding motivation, but should also be considered on the basis of the validity of self-reports with respect to other sources of information.

Second, the emphasis of recent studies on the (low prosocial or even antisocial character of the) way religious people seem to react toward outgroup individuals has somewhat masked the research interest in the question whether religion may have some positive impact on prosociality at least: (a) when the in- versus outgroup character of a target is not activated; or (b) for some targets, in some contexts, and under some conditions.

\section{The Present Studies}

The main assumption of the present studies was that the theoretical evidence in favor of a possible - probably limited - effect of religion on prosociality is so strong and systematic across authors that the empirical evidence accumulated on the basis of self-reports makes it difficult to accept that religious people are in a state of self-delusion or even lying when they perceive themselves as agreeable, prosocial, helpful, and forgiving. Of course, if an effect exists, this is likely to be limited, and the quasi-experimental studies cited above indicate some of these limits (i.e., motivation as not purely altruistic, and lack of prosociality toward targets who threaten values).

The four studies reported here attempt to verify whether religiousness implies at least some prosocial tendencies and behaviors (other than the established effect of religion on volunteer work 
and financial charity; Spilka et al. 2003) using measures other than self-reports, i.e., projective measures, for Studies 1 and 2; peer ratings for Studies 3 and 4; and a quasi-experimental design for Study 2.

We investigated three main questions. First, we assumed that there is no reason to expect religiousness (in samples of people with average religiousness) to necessarily imply high-cost, "heroic" standards of altruism and prosocial behavior. Religiousness may, however, be associated at least with a "minimum" level of prosociality, such as low aggression. Of course, there is some evidence that aggression can be considered as a dimension independent from altruism (e.g., Krueger, Hicks, and McGue 2001) and that some moderate levels of aggression (rather reflecting assertiveness) may be beneficial for some types of prosocial behavior (Eisenberg and Fabes 1998), but overall it is well established that hostility and aggression are negatively related to agreeableness and prosocial traits and behaviors (e.g., Gleason, Jensen-Campbell, and Richardson 2004; Laursen, Pulkkinen, and Ryan 2002; Martin, Watson, and Wan 2000). Religious moral standards strongly condemn aggression, be it physical, verbal, or even "mental" - in early Christian spirituality, for instance, judging someone else negatively was considered similar to killing (Saroglou 2001). We hypothesized then that religious persons tend not to express aggressive tendencies when interacting with people.

Second, if it is once again less obvious that religiousness predicts high standards of prosociality toward, for instance, any kind of target (universalistic generalized prosociality), we at least expected religiousness to predict prosociality with regard to targets with which people are familiar and entertain close relationships and regular interactions. If prosocial religious ethics have any impact on people's lives, this should at least be manifest with close and familiar people: "brothers-sisters" and "neighbors" whose judgment and perception is valued, and with whom religious people are engaged in relationships implying reciprocity. We thus expected religiousness to predict the helping of close targets in need, but to be unrelated to helping unknown targets.

Third, another way to investigate whether religious people are "honest" toward others and themselves when they report high altruism and prosociality, or whether they maintain a kind of "self-delusion," is to ask others to evaluate religious people's altruism and prosociality. Peer ratings are extremely rare in psychology of religion and may be particularly valuable as a way of testing the relevance of the suspicion relative to the idealized self-perceptions of religious people regarding many personal aspects (e.g., positive personality traits, subjective well-being and mental health, security in attachment, marital satisfaction). Of course, peer validation of religious prosocial tendencies is not direct proof of prosociality, but at least it challenges the suspicion of dishonesty or self-delusion in religious people when they provide high scores on agreeableness and prosociality.

Finally, across the four studies reported below, some other questions were investigated. First, if some limited prosocial tendencies can be documented as a function of religiousness, is this because religious people are empathetic, can feel and understand what others feel, and are affected by others' suffering or needs? Or is it because they are willing to conform to the ideal of a correct and fair person, to the ideal of respecting some important (prosocial) ethical principles? An important distinction between such an empathetic versus principled motivation of prosociality exists both in philosophical and psychological literature on the subject (Batson et al. 2002; Dovidio and Penner 2002). Some previous evidence suggests an association between religiousness and at least selfreported empathy (see Batson, Schoenrade, and Ventis 1993, for a review; Luyten, Corveleyn, and Fontaine 1998; Schieman and Van Gundy 2000) and moral integrity-honesty (Spilka et al. 2003; see also Jones 1997; Katz, Santman, and Lonero 1994). Second, as women are known to be higher in both religiosity (Beit-Hallahmi and Argyle 1997) and, to some extent (see Eisenberg and Fabes 1998, for a discussion), agreeableness-related constructs (Costa, Terracciano, and McCrae 2001), gender may be responsible for the religiousness-prosociality association.

Third, some studies from the attachment research tradition underline the role of secure attachment on being open to others' needs, empathetic, and ready to help (e.g., Iannotti et al. 1992; Mikulincer et al. 2001; van der Mark, van IJzendoorn, and Bakermans-Kranenburg 2002). In 
addition, the recent body of research on attachment and religion suggests that people who are religious at a given point in time (and who have been successfully socialized in the context of religion) may be somewhat more likely to report secure attachments (Granqvist and Hagekull 1999; Kirkpatrick 1999a). It could then be that prosociality as a function of religiousness isat least partially - due to security in attachment. We thus investigated, in a few of our studies, whether empathy, moral integrity, gender, and security in attachment may explain the impact of religiousness on prosociality.

Overall, across the studies, the main emphasis was placed on general, personal religiousness, which can be considered as intrinsic religiosity in the context of the country where the studies were carried out. We did not distinguish between the three classic dimensions, intrinsic, extrinsic, and quest, that may predict different outcomes regarding prosocial behavior (Batson, Schoenrade, and Ventis 1993, Batson et al. 1999; Batson et al. 2001; Goldfried and Miner 2002). The reason for this is, first, that we may expect extrinsic religiosity to be more or less absent from highly secularized countries, where being religious (especially among young people) is more likely to reflect a personal, intrinsically motivated decision or inclination. Second, the low level of average religiosity in these countries makes it difficult to distinguish between a general proreligious tendency and specific religious dimensions, such as intrinsic, extrinsic, and quest, when data are collected in samples from the general population (and not from groups known to be religious). However, we were careful to make a distinction between religiosity and spirituality, since an emerging debate exists on whether contemporary spirituality implies individuality and self-interest or highly internalized prosocial values (see, e.g., Bellah et al. 1985; Dillon, Wink, and Fay 2003). In addition, with regard to the hypothesis on aggression, we made a distinction between religiosity and religious fundamentalism, since theoretically the latter is expected not to reflect low aggression and even to reflect high aggression: religious fundamentalism is strongly related with authoritarianism, a construct defined in part by authoritarian aggression (Altemeyer 1996).

\section{STUdY 1}

In this study, we tested the hypothesis that religiousness is negatively associated with indirect, nonphysical aggression. Since previous evidence documenting this link is usually based on selfreport questionnaires (e.g., Hills et al. 2004; Mahoney et al. 1999; Storch and Storch 2002), we were interested in whether this link can also be found through a projective measure, when participants face hypothetical frustrating situations, the latter being known to increase likelihood of aggressive answers (Geen 1998; Rosenzweig 1976). Since our assumption was that there are no reasons for religious people to be moral hypocrites, especially with regard to "minimal" prosociality (low aggression), we hypothesized a negative association between religiousness and indirect aggression as produced spontaneously in reaction to hypothetical situations. We thus adopted a research design where participants were unaware of the aims of the study and no prosocial value was activated, in contrast to self-report measures explicitly referring to hostilityaggression.

A second aim of this study concerned religious fundamentalism (RF) and was explorative. If we take into account the theoretical and empirical links of RF with right-wing authoritarianism (RWA), a construct in which authoritarian aggression is an important component (Altemeyer 1996), religious fundamentalists may be expected to express a certain level of aggression. Religious fundamentalism can be analyzed into two components: Christian Orthodoxy and RWA (Laythe et al. 2002). However, some studies, from a personality perspective, documented a weak but positive link between RF and Big Five agreeableness (Saroglou 2002a, for review). These latter findings could be understood as resulting from the pro-religious component of the RF construct: RF is usually intercorrelated with measures of religiosity. It then becomes interesting to explore whether RF predicts aggression, especially when religiousness is statistically partialled out in the analyses. 


\section{Method}

\section{Participants}

This study consists of a new analysis of data previously collected in order to measure the links between religion and sense of humor, operationalizing the latter as spontaneous humor creation (Saroglou 2002b; Saroglou and Jaspard 2001). Participants were 106 psychology students (33 men and 73 women) from a French-speaking university in Belgium who chose to take part in this study in order to obtain credit for their introductory psychology course. The study was advertised as a study in "coping and styles in which individuals cope with stressful situations." Participants were administered the measures either individually or in small groups.

\section{Measures}

Participants were asked to fill in the punchlines of all the 24 pictures of the Rosenzweig (1948) test presenting frustrating daily life situations. The test was administered with the usual instructions inviting individuals to imagine how they would react in the situations depicted. Whereas these data were previously analyzed to detect spontaneously produced humor, we decided to also analyze them for aggression. Indeed, the situations depicted in the Rosenzweig test are intended to produce frustration and subsequent aggression in the participants' answers to a situationsentence initiated by a protagonist (Rosenzweig 1976). However, the coding system adopted by Rosenzweig is extremely complex; criticism exists on whether the high degree of sophistication in coding corresponds to a highly subtle measure of aggression and the test is today considered rather outdated. We thus decided to simplify the analysis by simply coding the answers as: (1) kind, polite; (2) neutral or ambiguous about the feelings of the person who answers; or (3) aggressive (impolite, arrogant, insulting, threatening, accusing). We did not distinguish between intropunitive and extrapunitive aggression, between situations differing in source of frustration, or between different degrees of aggressive answers. The latter distinction would be interesting but highly subjective.

The following are two examples of coding. First, in a situation where four friends (two vs. two) are playing cards and one of the partners apologizes to the co-player for having made an important error, the co-player (participant of the study) may answer as follows: "Don't worry about it. We'll win next time" (kind, polite); "Oh well" (neutral, ambiguous); or "You can't even bloody play ... I want to change teams" (aggressive). Second, in a situation where the protagonist is complaining because the other person has broken a vase belonging to the protagonist's grandmother, the other person (participant of the study) may answer: "Sorry, I'll replace it with a new one" (polite); "Are you sure that she still likes it?" (neutral, ambiguous); or "Oh shut up about your grandmother and her inheritance" (aggressive).

Keeping information on participants masked (e.g., religiosity, gender), two psychologists, one male and one female, coded the answers; the interrater reliability was satisfactory $(R=0.79)$. The total score on aggression (in fact, a high score on the continuum from kindness to "verbal" aggression as transmitted on paper) was obtained by summing up the scores on answers to the 24 pictures $(\alpha=0.70)$.

Afterward, participants were administered a three-item religiosity index $(\alpha=0.86)$ asking for evaluation of (a) the importance of God in personal life; (b) the importance of religion in personal life; and (c) the frequency of prayer. Questions (a) and (b) were evaluated through a seven-point Likert scale and question (c) through a five-point scale. In addition, our French translation of the 20-item religious fundamentalism scale (Altemeyer and Hunsberger 1992) was also administered to our participants $(\alpha=0.78)$. Examples of the RF items are: "All of the religions in the world have flaws and wrong teachings" (reverse); "To lead the best, most meaningful life, one must belong to the one, true religion." 


\section{Results and Discussion}

Not surprisingly, men tended to be lower in religiosity, $t=-3.37, p<0.01$, and higher in aggression, $t=3.32, p<0.01$, than women. The mean on the aggression-kindness continuum, $M(S D)=43.99$ (5.90), was almost the same as the median (44.5; minimum and maximum values obtained $=30$ and 59), and this may hopefully be considered as normal. No gender differences were observed on religious fundamentalism.

As hypothesized, religiosity was negatively correlated with aggression, $r=-0.25, p<0.01$. When controlling for gender, the correlation decreased but remained significant, $r=-0.17$, $p<0.05$. Interestingly, religious fundamentalism (RF) was unrelated to aggression, $r=0.01$, and when controlling for religiosity in order to distinguish between the pro-religious and the fundamentalism components in the RF construct (RF and religiosity were intercorrelated, $r=$ $0.49), \mathrm{RF}$ was positively, although not significantly, related to aggression, $r=0.15$.

The main hypothesis was then confirmed: the more people value God and religion in their life and pray, the less they tend to spontaneously react in an aggressive way when faced with hypothetical daily hassles that occur within the framework of interpersonal relations-or to say it in other words, the more they tend to react in a polite and conciliatory way. This was not the case with fundamentalism, especially when its overlap with the pro-religious tendency was partialled out, a finding suggesting that when previous studies have found fundamentalism to be positively related to self-perceived agreeableness (see Saroglou 2002a, for a review), they may have confounded the fundamentalist and the pro-religious components included in the RF construct (note that in these studies, and in the present one, the RF scale is administered on samples including both religious and nonreligious participants). Similarly, Laythe et al. (2002) have found that it was the RWA and not the Christian Orthodoxy component of RF that predicted prejudice.

\section{STUdY 2}

If low aggression, at least low indirect aggression as spontaneously produced through a projective measure, may constitute one behavioral aspect of the minimal prosociality of religious people, another aspect of this prosociality may be the willingness to help at least close people, i.e., family members and close friends and colleagues with whom religious people interact frequently and with whom they feel somewhat engaged in a concrete relationship. We hypothesized that religiousness is positively related with willingness to help family members and close relations; however, this willingness may not be extended to unknown targets, i.e., people with whom no relationship has been engaged, a situation that does not include reciprocation and benefits from a positive perception by these targets.

A second aim of this study was to investigate the possible impact of security in attachment to parents on the relation between religiousness and helping close and/or unknown targets. Security in parental attachment is a basis for prosocial behavior and empathetic concern in general (Iannotti et al. 1992; Mikulincer et al. 2001; van der Mark, van IJzendoorn, and Bakermans-Kranenburg 2002), but also a basis for positive relations and prosocial behavior with family members and close relations (e.g., Eberly and Montemayor 1998). In addition, religiousness, at least in the case of socialization-based religion, reflects high security in parental attachment (Kirkpatrick 1999a). It could then be that religious people are likely to help close targets because of their secure attachment rather than because of their religiousness per se.

\section{Method}

\section{Participants}

Participants were 111 students from a psychology college in Brussels (mean age $=19.76$ years, $S D=2.11$ ). Only six young men were found in this class, so the analyses were carried out 
on the 105 young women in order not to add the possible noise of gender differences, impossible to control given the limited number of men. Students were asked to participate in the study during class, but they were allowed not to partake in the study if they so wished.

\section{Measures}

Prosociality. The study was presented as a study in "styles of reacting in the face of everyday life situations." Participants were administered a written description of nine hypothetical situations, typical of everyday life interpersonal interactions (nine paragraphs). In five of them a person is clearly in need (asks for help with homework, asks for help during exams, asks to pass first in the queue because only has one item to buy, has an open suitcase when trying to catch the train) or may be forgiven (the protagonist meets the target accidentally a day after the target misbehaved). The hypothetical situations were designed by the authors so as to restrict reaction options: constraints (be in a hurry, have work to do, impossibility of avoiding the target) were designed such that the protagonist could only decide whether to be prosocial or not. In order to avoid the activation of prosociality (at least with any certainty) as an implicit research hypothesis by the participants, we remained ambiguous about the goals of the study by alternating the above situations with four additional situations describing intriguing, amazing, or stressful events that also ask for a reaction-decision that had nothing to do with prosocial concerns: somebody is wearing the same clothes at a party, you have burnt the meal when inviting people for dinner, nobody else is laughing when watching a movie, you misidentify someone in the street. In each case, participants had only two lines to say how they would react if they were faced with these situations.

Two versions of the hypothetical situations were randomly distributed. In the first versioncondition, the protagonist in need was presented as a member of the family or a (class or work) colleague or a friend. In the second condition, the situations were the same but the protagonist was presented as an unknown person. Sample sizes by condition were $N=52$ for the close target condition and $N=53$ for the unknown target condition.

Two psychologists, one male and one female, coded the answers in the five prosocialityrelated situations as (1) not prosocial; (2) conditionally prosocial (expressing prosocial intentions but under some conditions such as the low cost of helping, the motives of the person in need); or (3) unconditionally prosocial (people only mentioned their prosocial choice without limiting it by some conditions). In 70 percent of the 515 cases ( 5 situations $\times 105$ participants), there was an interrater agreement. The total score by subject on prosociality was calculated by averaging the answers (coded as 1,2, and 3 as in a continuum) in the five prosociality-related situations.

Religiousness. Participants were administered an eight-item scale of religiousness that has demonstrated a clear structure of three factors in a total of 2,000 participants from our previous studies. This structure has recently been replicated in three culturally different samples of young adults living in Belgium, i.e., native (Catholic tradition), Muslim immigrants from Mediterranean countries, and other immigrants (Saroglou and Galand 2004). The scale includes (a) a three-item religiosity index (also used in Study 1: importance of God in personal life, importance of religion in personal life, and frequency of prayer); (b) a four-item emotional religion index (interest in emotional-relational aspect, community aspect, meaning-values, and personal experience in religion); and (c) a one-item spirituality index (importance of spirituality in life). As in previous studies, data in the present study provided high reliabilities $(0.89$ for religiosity, and 0.87 for emotional religion) and moderate-to-important intercorrelations between the three dimensions ( $r$ s varied from 0.57 to 0.76 ). Except for frequency of prayer (five-point), a seven-point Likert format scale is used for all items.

Attachment to Parents. We used the retrospective descriptions of attachment to parents (evaluated separately for father and mother) established by Hazan and Shaver (1987) in order to measure attachment styles through three different paragraphs each describing a secure, anxious/ambivalent, or avoidant attachment. As usually done in other studies, participants provided an evaluation of 
each of the three paragraphs in a Likert-type format (seven-point scales), a method that provides finer assessment of attachment than the simple categorical selection of one of the three paragraphs. In order to simplify presentation of the results, we followed Granqvist (2002) and, for each parent, combined the score on security and the inverted scores on the two insecurity dimensions. In fact, exploratory factor analyses of the six items provided a clear two-factor solution explaining 73 percent of the total variance (each factor included the three attachment items corresponding to each parent). Distinct factor analyses for each parent of the three attachment items each time provided a one-factor solution explaining 74 percent (father) and 71 percent (mother) of the total variance. The reliabilities of the two "global security" three-item measures were high, $\alpha \mathrm{s}=0.82$ (father) and 0.80 (mother), and the two measures were only moderately intercorrelated, $r=0.42$, $p<0.01$.

\section{Results and Discussion}

\section{Religiousness and Helping Close and Unknown Targets}

Participants varied on their willingness to help: minimum and maximum scores, without distinction of conditions $=1.00$ and 2.85 ; mean and standard deviation of prosociality scores by condition are detailed in Table 1. As also detailed in Table 1, participants in the close target condition expressed more willingness for a prosocial reaction than participants in the unknown target condition, a finding that is in line with the established literature (see, for an evolutionary perspective, Burnstein, Crandall, and Kitayama 1994).

As hypothesized, religiosity, both classic and emotional, was positively related to helping, but the effect was limited to the close target condition and did not extend to the unknown target condition. This can first be explained as resulting from the ingroup limitations of the prosocial character of religion, if we follow a sociobiological perspective: the a broader cultural kinship that extends, thanks to religion, the limits of natural Kinship's frontiers (Batson 1983). Second, it could be explained by the importance for religious people to be on "good terms" with and positively perceived by other people with whom a long-term interaction is established. Finally, family members and close persons such as friends and colleagues are supposed, within a religious perspective, to be partners in a relation that implies engagement and reciprocity.

Interestingly, contrary to religiosity measures, the importance of spirituality in life was associated with willingness to help both close and unknown targets. The present results are in line

TABLE 1

MEANS, STANDARD DEVIATIONS, AND CORRELATIONS OF PROSOCIAL BEHAVIOR TOWARD A CLOSE AND AN UNKNOWN TARGET WITH RELIGION (STUDY 2)

\begin{tabular}{lccr}
\hline & \multicolumn{2}{c}{ Helping } \\
\cline { 2 - 3 } & A Close Person $^{\mathrm{a}}$ & An Unknown Person $^{\mathrm{b}}$ & $T$-Test \\
\hline$M$ & 2.13 & 1.92 & $2.96^{* *}$ \\
$S D$ & 0.33 & 0.37 & \\
Correlations & & & \\
$\quad$ Religiosity & $0.38^{* *}$ & -0.01 & \\
Emotional religion & $0.21^{+}$ & 0.07 & \\
Spirituality & $0.33^{*}$ & $0.32^{*}$ & \\
\hline
\end{tabular}

${ }^{\mathrm{a}} N=52 .{ }^{\mathrm{b}} N=53$.

${ }^{*} p<0.05 .{ }^{* *} p<0.01 .{ }^{+} p<0.10$. 
with increasing evidence that modern changes on the religious landscape and an increase of importance attributed to spirituality are followed by a shift from ingroup-focused to universalistic ethics, values, and behaviors (Saroglou 2003; Saroglou, Delpierre, and Dernelle 2004).

\section{Impact of Attachment}

Finally, attachment history seemed unable to play a mediating role on the religion-prosociality relation. The results supported first what is called the correspondence model (see Kirkpatrick 1999a): participants high in religiosity tended to report secure attachment to father, $r(105)=$ $0.17, p<0.10$, and mother, $r(105)=0.20, p<0.05$. This was also somewhat the case with emotional religion, $r \mathrm{~s}=0.17, p<0.10$, and 0.14 , n.s., but not with spirituality, $r \mathrm{~s}=-0.04$ and -0.07 . However, security in attachment to father and mother was unrelated to the willingness to help the hypothetical targets of the described situations, both in the close target condition, $r \mathrm{~s}(52)=$ $0.22,-0.19$, n.s., and in the unknown target condition, $r \mathrm{~s}(53)=-0.15,-0.17$, n.s.

In order to be certain that the tendency of religious and spiritual people to help, respectively, known and unknown targets was not conditioned by high or low security in attachment, partial correlations were computed controlling for security in attachment to father and mother. After the two attachment measures were partialled out, religiosity was still positively correlated with the tendency for helping known persons, $r \mathrm{~s}=0.40, p<0.01$, and spirituality was still positively correlated with the tendency for helping unknown persons, $r \mathrm{~s}=0.28, p<0.05$. In conclusion, self-reported prosocial behavioral tendencies of religious and spiritual people toward close and/or unknown targets did not seem to reflect differences in attachment history.

\section{STUDY 3}

The main sources of information supporting the prosocial character of religious personality are self-reported data. One way of testing whether such information reflects only subjective selfperception, leading to a suspicion about self-delusion in religious people, or whether it reflects a more objective reality, is to investigate how others perceive religious people. Some initial studies provide peer information on this issue but these studies have important limitations. Almost 50 years ago, Clark and Warner (1955) found that church attendance was positively related to a person's kindness and honesty as evaluated by community members. In another study from the same decade (Friedrichs 1960), church attendance and belief in God were unrelated to the target's altruism as evaluated by fraternity members. In two more recent studies, it was found that religious young adults and adults in general were evaluated as high in agreeableness and conscientiousness by their mother (Saroglou and Fiasse 2003), and by their parents and teachers when the targets were adolescents (a cohort born in the 1920s; McCullough, Tsang, and Brion 2003).

In all these studies, however, the peers who provided these ratings may have been biased by the willingness to project to their children or members of their community their own idealized perception of personality. Religious children, for instance, are very likely to have religious parents, who in turn may perceive their children as agreeable because they themselves value prosocial ethics. The aim of our Studies 3 and 4 was thus to look for confirmation of the prosociality of religious targets by peers other than parents. For Study 3, we selected two kinds of peers, a sibling and a friend of the target. Both of these can be expected to know the target well, but also to have their independent perception of the target's personality.

In measuring prosociality in these two studies, we chose to focus on prosocial acts (through commonly used altruism scales) ${ }^{1}$ and empathy, a construct that includes (a) strictly empathetic concerns; (b) capacity for perspective taking; and (c) personal distress, which is also an empathyrelated emotion, although it may be an obstacle for undertaking prosocial action (Eisenberg and Fabes 1998). In addition, in order to understand the psychological processes underlying prosociality as a function of religiousness, we also explored whether the religiousness-prosociality 
link may mainly be due to empathy, a construct expected to be related both to religiousness and prosociality.

Finally, we included a measure of honesty, assumed to correspond to moral integrity (Ashton et al. 2004; Lee and Ashton 2004). The aim of including this measure was to explore whether the impact of religion on prosociality is based on affective-relational reasons (empathy) or on cognitive, ideological reasons, such as the willingness to be fair and respect ethical rules and principles. Both processes can be hypothesized. Religion may emphasize (e.g., through images and ideas of brotherhood and universal love) connectedness and relatedness to others, sharing others' feelings and emotions ("Rejoice with them that do rejoice, and weep with them that weep," Romans 12:15), and the need to understand the other's perspective. However, religion may also provide mechanisms (e.g., values and ideals) that emphasize the importance of being fair and correct, and of respecting moral maxims and principles that should be followed without cowardliness or excuses.

\section{Method}

\section{Participants}

The participants were 313 late adolescents and young adults. Students in three high schools in the French-speaking part of Belgium were asked to collaborate in a study whose focus was the diverging or similar perceptions different persons may have of the same target, in both a family and a friendship context. Each package contained three protocols with the measures, one in self-version for the target, and two in peer versions for one sibling and one friend to be selected by the target. In order to control for sibship size (this variable may have an impact on personality; Downey 2001), only targets from a three-sibling family were asked to participate. In total, 180 packets were distributed. A separate envelope (with the university logo) for each respondent was enclosed in the packet, and peer respondents were asked to return sealed envelopes to the target in order to ensure confidentiality and to avoid collaboration in answering. The target students returned the packet within three weeks to the school or sent it back to the researcher by mail. This strategy was used in order to maximize the rate of responses. In total, 105 self-reports, 103 corresponding sibling ratings, and 105 corresponding friend ratings were returned.

Minimum and maximum age, mean age, and standard deviation, respectively, were as follows for each type of evaluator: 16-34, 20.48, 2.78 (self); 15-31, 19.51, 4.05 (sibling); and 16-35, $21.24,3.77$ (friend). For each type of evaluator, gender was distributed for men as women as, respectively: 29.1 versus 70.9 percent (self); 43.7 versus 56.3 percent (sibling); 29.5 versus 70.5 percent (friend). Same-sex versus other-sex evaluations were distributed respectively as: 50.5 versus 49.5 percent (siblings), and 74.29 versus 25.71 percent (friend).

\section{Measures}

Altruism. The Altruism Scale of Rusthon, Chrisjohn, and Fekken (1981; our French translation) contains 20 items measuring the frequency with which someone (the target, here either in self- or a peer version) has acted in a prosocial way through a variety of 20 everyday life situations (mainly helping actions). A five-point Likert scale, from never to very often, was used in all items. A total average score of altruism (more exactly, prosocial acts, since the motivation is not taken into account) was computed. The only cultural adaptation that seemed necessary was to delete the context of "snow" from Item 1. Examples of the scale items are: "I have, before being asked, voluntarily looked after a neighbour's pets or children without being paid for it"; "I have helped carry a stranger's belongings (books, parcels, etc.)"; "I have offered to help a handicapped or elderly stranger across the street." 
Empathy. The Interpersonal Reactivity Index (IRI; Davis 1983; French translation by P. C. Morin of University of Laval) consists of four subscales $(4 \times 7=28$ items): (a) empathetic concern, i.e., the tendency to experience compassion and concern for other (unfortunate) people; (b) perspective taking, i.e., the tendency to spontaneously adopt the viewpoint of other people in everyday life; (c) personal distress, i.e., the tendency to feel unease and anxiety in tense interpersonal settings; and (d) fantasy, i.e., the tendency to transpose oneself imaginatively into the feelings and actions of fictitious characters in books, movies, and plays. For our study, in order not to make the questionnaire too long, we did not administer the fantasy subscale, which seemed to us less relevant with regard to religiousness (for instance, openness to experience is unrelated to religiousness in general; Saroglou 2002a, in press). A five-point Likert scale was used (here for either self- or peer ratings) varying from "does not describe me (or him/her) at all" to "describes me (him/her) very well." Examples of the items are: "Other people's misfortunes do not usually disturb me a great deal" (reverse; empathy); "Before criticizing somebody, I try to imagine how I would feel if I were in their place" (perspective taking); "When I see someone who badly needs help in an emergency, I go to pieces" (personal distress).

Honesty. In order to measure a principled prosocial tendency, based on respect for moral integrity, we used the honesty subscale of the 108-item HEXACO (Six-Factor) Personality Inventory (French translation: Boies et al. 2004). This subscale (18 items) measures fairness, sincerity, and (to some extent) humility, as opposed to slyness, hypocrisy, manipulation of others, and breaking laws in the pursuit of selfish gains. With respect to the tradition of the Big Five personality factors, the distinctiveness of a sixth honesty-like personality factor (other terms advanced: Morality, Sincerity, or Integrity) from the other Big Five factors has received cross-cultural validation in non-English lexical studies (Ashton et al. 2004). The HEXACO Personality Inventory has recently emerged as an important measure of the "traditional" five plus the honesty factors (see Lee and Ashton 2004 for psychometric properties; see Boies et al. 2004 for psychometric properties of the French translation, including score distributions, reliabilities, intercorrelations, and relations with markers of the Big Five). Interestingly, the honesty subscale has been found to explain much more variance than agreeableness and conscientiousness in workplace delinquency or in sexual harassment, much in the same way as integrity tests do (see Lee and Ashton 2004). Theoretically, honesty includes the reciprocity-related construct of fairness and is thus distinct from conscientiousness (which includes task-related traits), the kin-altruism-related construct of empathy-attachment (agreeableness-minus-emotional stability axis), and the other reciprocityrelated construct of forgiveness (agreeableness-plus-emotional stability axis) (Ashton and Lee 2001). In this subscale, the target was evaluated on a five-point Likert scale. Examples of the scale items are: "I don't see anything wrong with using flattery to get ahead in life" (reverse); "I wouldn't cheat on an exam, even if I knew that I could get away with it."

Religiousness. Finally, the targets were provided with our three-item religiosity index ( $\alpha$ in this study $=0.81$ ) and our one-item importance of spirituality index (see Study 2). Spirituality was only moderately correlated with religiosity, $r=0.49$, which justifies its use as a distinct construct.

\section{Results and Discussion}

\section{Preliminary Analyses}

Means, standard deviations, and reliabilities of the measures, separately for each evaluator, are presented in Table 2. The target's gender had an impact on both self- and other-reports. Women evaluated themselves higher than men in personal distress, $t=2.16, p<0.05$, and honesty, $t=$ $3.40, p<0.01$. The first difference was confirmed by the siblings, $t=2.25, p<0.05$, and the second, with a marginal significance, by the friends, $t=1.71, p<0.10$. Moreover, women tended, with a marginal significance, to be perceived as higher in empathy by both peers, siblings and friends, $t \mathrm{~s}=1.82,1.92, p<0.10$. We thus included the target's gender as a covariate in 


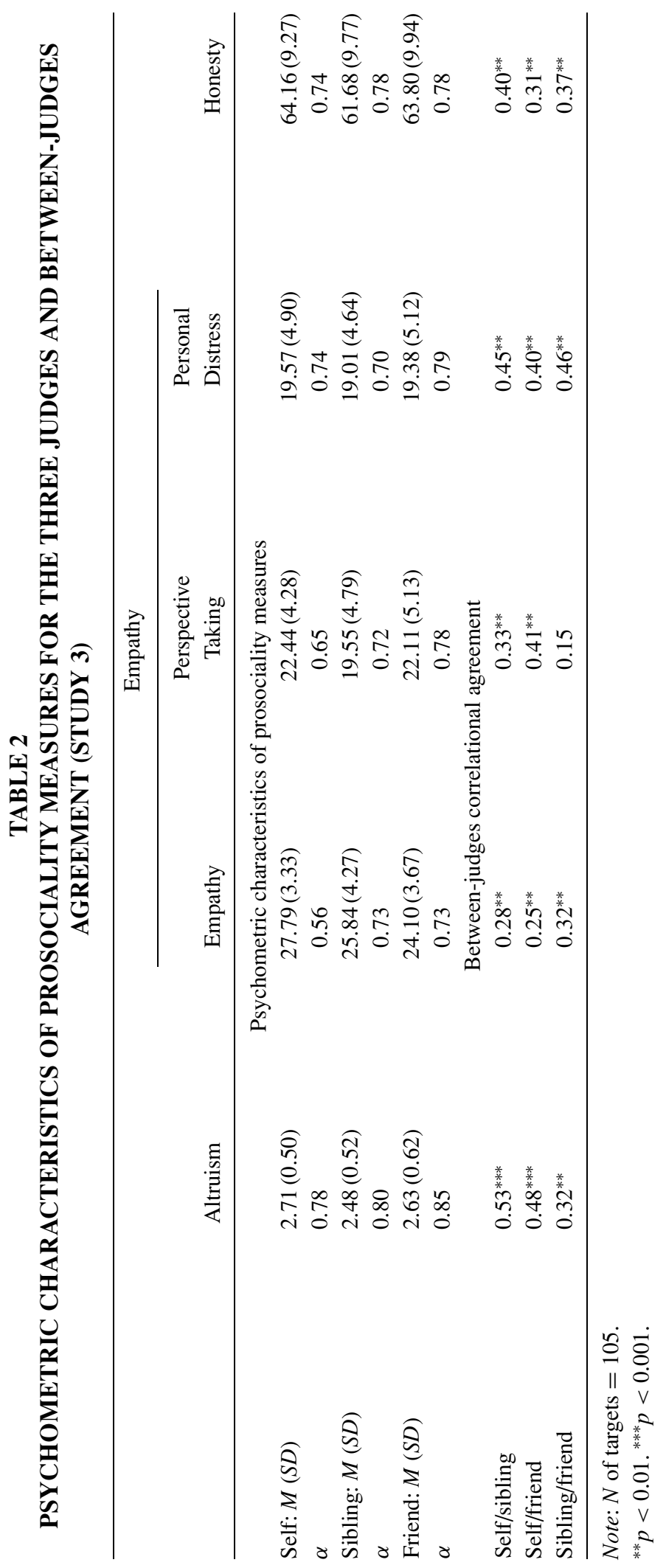


the subsequent analyses. However, the peers' gender had no impact on their perception of the prosociality and honesty of the target ( $t$-test comparisons between men and women were carried out, separately for siblings and friends) and was thus not included in the subsequent analyses. Finally, we were interested in whether the peer evaluations were influenced by either same-sex or opposite-sex relations to the target. Two-way ANOVA analyses, carried out separately for the sibling and friend ratings, did not indicate an effect of the same- versus opposite-sex status on any of the five evaluations (altruism, three components of empathy, and honesty). Thus, we did not include the cross-gender variable in subsequent analyses.

As also detailed in Table 2, there was considerable peer validation of the target's self-reports on prosociality measures since the latter were positively correlated with both sibling and friend ratings; the correlations between the sibling and the friend ratings also indicated between-peers agreement.

\section{Religion and Prosociality}

Three series of partial correlations (controlling for the target's gender) were computed between religiosity and spirituality of the target, on the one hand, and the target's altruism, empathy, and honesty as evaluated by each of the three observers (self, sibling, and friend), on the other. As detailed in Table 3, religion measures were, first, unrelated to personal distress both in selfand peer ratings. Second, in conformity with our expectations, religiosity and spirituality of the target were positively related to self-reported altruistic behavior; this relation turned out to be confirmed by siblings and friends. Third, spirituality (but not religiosity) was positively related to perspective taking and the friend ratings confirmed this link. Fourth, interestingly, although there was no relation between religiosity or spirituality of the target and self-reported empathy, such a relation was positive and significant according to siblings' (with religiosity) and friends' (with spirituality) ratings.

Finally, as also detailed in Table 3, religion was unrelated to honesty across all evaluations (with the exception of a positive association between spirituality of the target and honesty as perceived by the sibling). However, correlational analyses separated by gender indicated a moderating effect of gender. Religious men tended to report high honesty ( $r \mathrm{~s}=0.39, p<0.05$, for

TABLE 3

COEFFICIENTS OF PARTIAL CORRELATIONS (CONTROLLING FOR GENDER) BETWEEN TARGET'S RELIGIOSITY AND SPIRITUALITY, AND RATINGS OF PROSOCIALITY, DISTINCTLY FOR THE THREE JUDGES (STUDY 3)

\begin{tabular}{lllccr}
\hline & & \multicolumn{3}{c}{ Empathy } & \\
\cline { 3 - 4 } & Altruism & Empathy & Perspective Taking & Personal Distress & Honesty \\
\hline Self-reports & & & & & \\
$\quad \begin{array}{l}\text { Religiosity } \\
\text { Spirituality }\end{array}$ & $0.26^{* *}$ & 0.08 & 0.05 & -0.01 & -0.09 \\
Sibling ratings & $0.29^{* * *}$ & 0.10 & $0.28^{* *}$ & -0.03 & 0.09 \\
$\quad$ Religiosity & $0.18^{*}$ & $0.20^{*}$ & -0.06 & -0.00 & 0.10 \\
$\quad$ Spirituality & $0.25^{* *}$ & 0.15 & 0.10 & -0.03 & $0.25^{* *}$ \\
Friend ratings & & & & 0.03 & 0.00 \\
$\quad \begin{array}{l}\text { Religiosity } \\
\text { Spirituality }\end{array}$ & $0.19^{*}$ & 0.12 & -0.02 & -0.05 & 0.10 \\
\hline${ }^{*} p<0.05 .{ }^{* *} p<0.01 .{ }^{* * *} p<0.001$. & & $0.16^{*}$ & &
\end{tabular}


religiosity, and 0.22 , n.s., for spirituality) and were perceived as such both by their sibling $(0.28$, $p<0.10 ; 0.34, p<0.05)$ and their friend $(0.23$, n.s., $0.29, p<0.10)$. In women, however, honesty seemed to be rather unrelated to religion, although it was negatively related to religiosity in self-reports, $-0.23, p<0.05$, but positively related to spirituality in the sibling ratings, 0.21 , $p<0.05$.

\section{Predicting Altruism in Regression Analyses}

Altruism, empathy, and perspective taking were intercorrelated across the three evaluators ( $r \mathrm{~s}$ varied from 0.21 to 0.48 ), and the former construct was negatively related to personal distress in self-ratings $(-0.23)$. Across all three judges, honesty was related to empathy and perspective taking ( $r$ s varied from 0.26 to 0.41 ), and to a lesser extent to altruism (mean $r=0.16$ ); and it was unrelated to personal distress. Thus, in order to test the unique predictability of each component on altruism as well as the possible unique predictability of religion/spirituality beyond the overlap of the latter with empathy or perspective taking, we conducted three multiple regression analyses on altruism as it was rated each time by each evaluator (self, sibling, and friend). Each time, we included as predicting variables empathy, perspective taking, personal distress, and honesty as estimated by the corresponding evaluator, as well as the target's religiosity and gender.

As detailed in Table 4, across both the self- and the two peer ratings, altruism of the target was predicted by high scores on perspective taking and religiosity. According to the self-reports, altruism was also predicted by low personal distress (although personal distress is known to be an empathy-related emotion, it may be a handicap for prosocial action; Eisenberg and Fabes 1998). Computing again the same regression analyses with the target's spirituality instead of religiosity as predictor (including both constructs in the same analysis could lead to multicollinearity effects) replicated the above findings. Self-reported altruism was predicted by high perspective taking, $B=0.33, t=3.40, p<0.001$, low personal distress, $B=-0.19, t=-2.20, p<0.05$, and high spirituality, $B=0.17, t=1.96, p<0.05$. The target's altruism as perceived by the sibling was predicted by the target's spirituality, $B=0.21, t=2.16, p<0.05$, and by his or her perspective taking as evaluated by the sibling, $B=0.23, t=2.28, p<0.05$. This was also the case with the friend evaluations: $B=0.24, t=2.71, p<0.01$ for spirituality, and $B=0.37, t=3.58, p<0.001$ for perspective taking. In conclusion, religion (or spirituality) seemed to be a unique predictor of self-reported or other-perceived prosociality, and did not seem to be explained by, respectively, self-reported or perceived empathy nor honesty.

TABLE 4

MULTIPLE REGRESSION ANALYSES OF EMPATHY MEASURES, HONESTY, AND RELIGION ON ALTRUISM (STUDY 3)

\begin{tabular}{|c|c|c|c|c|c|c|}
\hline \multirow[b]{2}{*}{ Predictors } & \multicolumn{2}{|c|}{ Self-Reports } & \multicolumn{2}{|c|}{ Sibling Ratings } & \multicolumn{2}{|c|}{ Friend Ratings } \\
\hline & $B$ & $t$ & $B$ & $t$ & $B$ & $t$ \\
\hline Empathy & 0.12 & 1.28 & 0.08 & 0.73 & 0.10 & 0.94 \\
\hline Perspective taking & 0.37 & $3.95^{* * *}$ & 0.29 & $2.82^{* *}$ & 0.43 & $4.07^{* * *}$ \\
\hline Personal distress & -0.18 & $-2.15^{*}$ & -0.10 & -1.08 & 0.05 & 0.53 \\
\hline Honesty & 0.09 & 0.93 & 0.01 & 0.09 & -0.04 & -0.36 \\
\hline Target's gender & -0.16 & -1.77 & -0.18 & -1.82 & -0.02 & -0.19 \\
\hline \multirow[t]{2}{*}{ Target's religiosity } & 0.24 & $2.85^{* *}$ & 0.18 & $1.91^{*}$ & 0.19 & $2.09^{*}$ \\
\hline & \multicolumn{2}{|c|}{$R^{2}=0.36$} & \multicolumn{2}{|c|}{$R^{2}=0.18$} & \multicolumn{2}{|c|}{$R^{2}=0.25$} \\
\hline
\end{tabular}

${ }^{*} p<0.05 .{ }^{* *} p<0.01 .{ }^{* * *} p<0.001$. 


\section{STUDY 4}

The main aim of Study 4 was to replicate and extend Study 3 with a different sample (adults rather than students), a broader measure of prosociality expanded in range and scope (not only limited to strangers and organizations, as in the Rushton, Chrisjohn, and Fekken (1981) scale, but also including friends and acquaintances as targets), and different kinds of peers (adult friends and colleagues rather than siblings and late adolescent friends). Colleagues may be particularly important as peer evaluators. Contrary to siblings, with whom targets may be suspected to share similar values and worldviews, and friends, who are usually selected among other things because of common values and worldviews, colleagues are usually not selected. We had no reason to formulate hypotheses different from those of Study $3 .^{2}$ We thus expected religiousness and spirituality to be associated with self-reported altruism, empathy, and honesty, and that such associations would be confirmed by friend and colleague ratings. We also explored again whether prosociality as a function of religiousness may be explained by empathy and/or honesty.

In addition, we looked for the possible impact of social desirability (impression management and self-deception; Paulhus 1991) on the religion-prosociality association. Although empirical, including experimental, evidence suggests that social desirability may be considered as a substantial personality variable rather than a self-presentation bias (e.g., Ones, Viswesvaran, and Reiss 1996; Piedmont et al. 2000), psychology of religion scholars are still suspicious that the religion-altruism relation may be "false" as contaminated, for instance, by a self-presentation bias in the responses of religious participants (Eysenck 1998) and by the need of the latter to appear as following high moral standards (Batson, Schoenrade, and Ventis 1993).

\section{Method}

\section{Participants}

A total of 250 adults were approached; 86 of them were French-speaking Belgians and 164 Dutch-speaking Belgians. One-third of these were recruited at a weekend for pastoral workers, the others through acquaintances from social environments that were not specifically religious. All were informed that the goal of the study was to investigate how perception of the same person may vary or be similar across different evaluators. They were given an envelope with three protocols, one for themselves, one for a friend, and another for a colleague of their choice. They were asked to give the two other protocols to a same-sex friend and colleague (this instruction allowed us to neutralize the possible effect of the judge's gender and its interaction with the target's gender). Each of the three evaluators sent the questionnaires back to the researchers individually and anonymously. The target participants were finally 109 adults (38 French speaking and 71 Dutch speaking; 36 men and 70 women, 3 without mention of sex) who sent back their protocols. Minimum, maximum, mean, and standard deviation of age were 17, 68, 32.74, and 14.2, respectively. There were 88 friends who responded (minimum, maximum, and mean age were $17,74,33.58$, and 16.2, respectively) as well as 77 colleagues (minimum, maximum, mean, and standard deviation of age were $18,65,34.45$, and 14.1, respectively). The numbers of pairs of evaluators were 79 (self/friend), 72 (self/colleague), and 60 (friend/colleague). The evaluators completed a self- (by the target) or a peer (by the friend and colleague) version of measures evaluating the target's altruism, empathy, and honesty. In addition, the target responded to a measure of religiousness and social desirability. Participation was voluntary, and participants were provided with the option to be informed of the results of the study.

\section{Measures}

Altruism. For measuring altruism, we used the questionnaire created by Krueger, Hicks, and McGue (2001) that extended the Self-Report Altruism Scale of Rusthon, Chrisjohn, and Fekken 
(1981). Many items are taken from the latter scale but many new items are added to expand upon the range and scope of altruistic actions. The targets to be helped are strangers and organizations (as in Rushton et al.'s scale) but also friends and acquaintances. We used 38 of the 45 items of the scale (Items 3, 6, 20, 21, 25, 26, 37 seemed irrelevant to us for the social context of the country of our study). A five-point Likert scale was used for all items. Examples of the scale items were: "I have helped an acquaintance at work finish a project or solve a problem, even though I did not get any credit for the work"; "I have changed my plans so that I could help out a close friend"; "I have delayed the elevator so that a stranger would not be left behind"; "I have done volunteer work for a charity or community service organization."

Empathy. We used the 21 items of the Davis (1983) empathy scale (Interpersonal Reactivity Index) measuring empathy, perspective taking, and personal distress (see Study 3).

Honesty. The honesty subscale of the HEXACO personality measure was used again (see Study 3).

Religiousness. As in Study 2, we used our eight-item religiousness scale measuring (classic) religiosity ( $\alpha$ in this study $=0.91$ ), emotional religion ( $\alpha$ in this study $=0.88$ ), and spirituality.

Social Desirability. We included 20 items (seven-point Likert format scale) from the validated French scale of social desirability (Tournois, Mesnil, and Kop 2000; total 36 items) measuring the two dimensions of social desirability $(2 \times 10$ items $)$, i.e., impression management and selfdeception, similarly to the Paulhus (1991) Balanced Inventory of Desirable Responding (BIDR). The 20 items were selected on the basis of results from a previous study (Saroglou and Galand 2004) on 250 young adults, where these items were found to clearly constitute two distinct and unrelated $(r=0.08)$ factors. In our data, the two dimensions were replicated when asking for extraction of two factors in a principal component analysis with varimax rotation. The two factors explained 40 percent of the total variance. Reliabilities were satisfactory $(0.78$ for impression management, and 0.83 for self-deception); the two dimensions were negatively intercorrelated, $r=-0.23, p<0.05$. Examples of the items are: "I always speak well about others"; "I always listen carefully when others are speaking to me" (impression management); "Sometimes I'm sad"; "Sometimes I doubt my own abilities" (self-deception).

\section{Results and Discussion}

\section{Preliminary Analyses}

Means, standard deviations, and reliabilities of the measures, separately for each evaluator, are presented in Table 5. Similarly to Study 3, the target's gender had an impact both on selfand peer reports. In comparison with men, women perceived themselves higher in empathy and honesty, $t \mathrm{~s}=3.00,3.30, p<0.01$, which was also perceived by the colleague, $t \mathrm{~s}=2.74, p<$ 0.01 , and 2.03, $p<0.05$. They also perceived themselves to be higher in personal distress, $t=$ 2.83, $p<0.01$, which was confirmed by their friends, $t=3.09, p<0.01$. We thus included the target's gender as a covariate in subsequent analyses.

As detailed in Table 5, there was a moderate-to-considerable agreement between the target and each of the two peers in their ratings on all measures. A between-peer agreement was also found on empathy, personal distress, and honesty, but not on altruism and perspective taking.

\section{Religion and Prosociality}

As detailed in Table 6, partial correlations between religion measures and prosociality constructs, controlling for the target's gender, indicated that the target's religiousness and spirituality were positively related to self-reported altruism (all religion measures), empathy, and perspective taking (two out of the three religion measures). In addition, religiosity was positively related to 


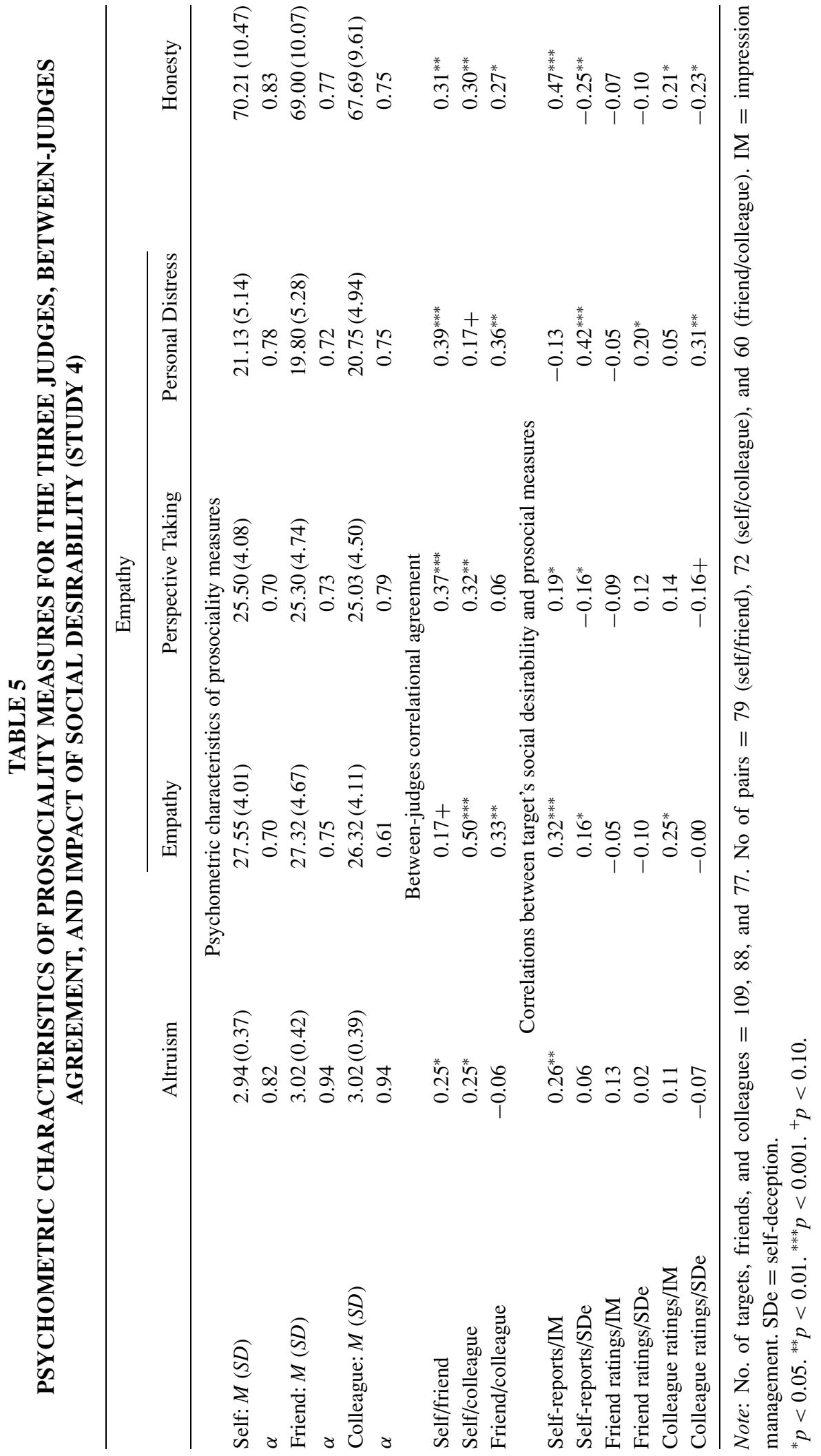




\section{TABLE 6 \\ COEFFICIENTS OF PARTIAL CORRELATIONS (CONTROLLING FOR GENDER) BETWEEN TARGET'S RELIGIOSITY AND SPIRITUALITY, AND RATINGS OF PROSOCIALITY, DISTINCTLY FOR THE THREE JUDGES (STUDY 4)}

\begin{tabular}{|c|c|c|c|c|c|}
\hline & & & Empathy & & \\
\hline & Altruism & Empathy & $\begin{array}{c}\text { Perspective } \\
\text { Taking }\end{array}$ & $\begin{array}{c}\text { Personal } \\
\text { Distress }\end{array}$ & Honesty \\
\hline Self-reports & & & & & \\
\hline Religiosity & $0.27^{* *}$ & $0.27^{* *}$ & 0.11 & -0.03 & $0.24^{* *}$ \\
\hline Emot. religion & $0.31^{* * *}$ & $0.26^{* *}$ & $0.15^{+}$ & 0.05 & 0.11 \\
\hline Spirituality & $0.29^{* * *}$ & 0.10 & $0.28^{* *}$ & -0.03 & 0.09 \\
\hline Friend ratings & & & & & \\
\hline Religiosity & 0.01 & 0.05 & -0.02 & -0.05 & 0.04 \\
\hline Emot. religion & -0.01 & 0.00 & 0.00 & -0.08 & 0.01 \\
\hline Spirituality & 0.04 & 0.09 & 0.04 & -0.09 & 0.09 \\
\hline Colleague ratings & & & & & \\
\hline Religiosity & $0.19^{*}$ & $0.22^{*}$ & -0.07 & 0.14 & $0.20^{*}$ \\
\hline Emot. religion & 0.06 & $0.16^{+}$ & -0.08 & 0.15 & 0.07 \\
\hline Spirituality & $0.16^{+}$ & $0.18^{+}$ & -0.12 & -0.08 & 0.09 \\
\hline
\end{tabular}

self-reported honesty. Except for perspective taking, the above findings were confirmed by the colleague's evaluation: a religious target was perceived as altruistic (religiosity and spirituality), empathetic (all three religion measures), and honest (religiosity). However, the friend judgments did not confirm the prosocial tendency of the religious target, and this was the case with regard to all aspects of prosociality. Finally, similarly to Study 3, the target's religiousness and spirituality were unrelated to personal distress both in self- and peer ratings. Interestingly, analyses separated by gender indicated that, somewhat similarly to Study 3, the association between religion and honesty was clearer for men: religious men perceived themselves as honest $(r=0.25$, with religiosity) and were perceived as such by their colleagues ( $r \mathrm{~s}=0.45,0.38,0.22$, for religiosity, emotional religion, and spirituality) but not by their friends, whereas a link between religiousness and self-reported honesty of women ( $r \mathrm{~s}=0.25,0.17$, with religiosity and emotional religion) was not confirmed by the two peers. (It is possible that the religion-honesty association is stronger in men, who are generally lower than women both in religion and honesty.)

In conclusion, Study 4 replicated most of the results of Study 3. An important exception was that friends did not confirm the prosocial character of the religious target, although colleagues did. The reasons for this divergence are unclear. Both peer ratings were equally intercorrelated with self-reports, but the lack of between-peer agreement on altruism and perspective taking in this study suggests some divergence in evaluations between colleagues and friends. Since in Study 3 the friends confirmed the religious target's prosociality, the particularity of the friends' judgments in Study 4 cannot be attributed to their status as friends.

\section{Social Desirability Impact}

We followed two analytic strategies to verify whether the religion-prosociality relation is an artifact of social desirability, the latter dimension being suspected as reflecting a self-presentation bias that may be expressed either as impression management or self-deception. The first strategy 
consisted in carrying out partial correlations between religion and prosociality measures (selfreports) controlling for the target's social desirability. In the second strategy, following Ones, Viswesvaran, and Reiss (1996), we investigated whether the target's social desirability is related to peer ratings of the target's prosociality. If such a link exists, this can be considered to imply that social desirability represents a substantial personality variable reflecting (religious) people's prosocial tendencies rather than an intention to "lie" and make a good impression.

First, the target's religiosity, emotional religion, and spirituality were positively related to impression management, $r$ s (controlling for gender) $=0.39,0.37, p<0.001,0.21, p<0.05$, respectively, but were unrelated to self-deception, $r \mathrm{~s}=-0.02,0.04,0.01 .^{3}$ Social desirability was also related to prosociality measures: as detailed in Table 5, the target's impression management was positively related to self-reported altruism, empathy, perspective taking, and honesty, whereas self-deception was unrelated to self-reported altruism, positively related to empathy and personal distress, and negatively related to perspective taking and honesty. However, when partial correlations were conducted between the target's religiousness and self-reported prosociality, controlling for gender and impression management, the correlations (detailed in Table 6) decreased only slightly and remained significant: religiosity, emotional religion, and spirituality were related to self-perception as altruistic ( $r \mathrm{~s}=0.19, p<0.05 ; 0.24, p<0.01 ; 0.30, p<0.001)$, and empathetic $(0.17, p<0.05 ; 0.16, p<0.05 ; 0.15, p<0.10)$. Only the link between religiosity and honesty disappeared, $r=0.07$. (Additionally including self-deception as a control variable in the analyses did not change the above results.) Apparently, these results replicate previous studies (Lewis 1999, 2000) where it was found that, although social desirability has a slight impact on the association between religion and prosocial personality (measured in terms of low psychoticism), it cannot mediate nor thus explain the above relationship as being an artifact of a self-presentation bias.

Second, as also detailed in Table 5, the target's impression management was unrelated to his or her perception by the friend as prosocial, but it was positively related to the colleague's judgment of the target's prosociality in two cases: empathy and honesty. Interestingly, the target's empathy and honesty as evaluated by the colleague was also correlated to the target's religiosity. Moreover, adding impression management to gender as a control variable in partial correlations between the target's religiosity and the colleague's judgment of empathy and honesty importantly decreased the associations found previously (Table 5): $r \mathrm{~s}=0.14,0.13$, n.s., for empathy and honesty, respectively. ${ }^{4}$ Thus, following the rationale developed by Ones, Viswesvaran, and Reiss (1996), one concludes that social desirability reflects a true, substantial personality disposition rather than a bias in the religion-prosociality relation. Moreover, as stated by Ones, Viswesvaran, and Reiss (1996:670), "partialing social desirability from personality scale scores is likely to remove some true variance from the measures of personality."

\section{Predicting Altruism in Regression Analyses}

Intercorrelations between prosociality constructs were very similar to those in Study 3. Altruism, empathy, and perspective taking were intercorrelated across the three evaluators ( $r$ s varied from 0.22 to 0.48$)$. Personal distress was negatively related to altruism in friend ratings $(-0.17)$ and to perspective taking in sibling ratings $(-0.24)$, but, in this study, was positively related to empathy (mean $r=0.22$ ). Across all three judges, honesty was related to empathy and perspective taking ( $r$ s varied from 0.29 to 0.33 ), and to a lesser extent to altruism (mean $r=0.14$ ); and it was unrelated to personal distress. Consequently, the same multiple regression analyses were conducted on altruism as in Study 3, one for each kind of rating. Included as predictor variables were empathy, perspective taking, personal distress, and honesty, as well as the target's religiosity (or spirituality for the self-ratings, as it was a stronger correlate of altruism than religiosity), and gender. As indicated in Table 7, similarly to Study 3, the target's altruism was predicted in both self-reports and colleague evaluations of the target's perspective taking and religiosity or 


\section{TABLE 7 \\ MULTIPLE REGRESSION ANALYSES OF EMPATHY MEASURES, HONESTY, AND RELIGION ON ALTRUISM (STUDY 4)}

\begin{tabular}{|c|c|c|c|c|c|c|}
\hline & \multicolumn{2}{|c|}{ Self-Reports } & \multicolumn{2}{|c|}{ Friend Ratings } & \multicolumn{2}{|c|}{ Colleague Ratings } \\
\hline & $B$ & $t$ & $B$ & $t$ & $B$ & $t$ \\
\hline Empathy & 0.26 & $2.38^{*}$ & 0.53 & $4.56^{* * *}$ & 0.14 & 0.98 \\
\hline Perspective taking & 0.22 & $2.38^{*}$ & 0.00 & 0.04 & 0.36 & $2.83^{* *}$ \\
\hline Personal distress & -0.05 & -0.46 & -0.17 & -1.51 & 0.01 & 0.06 \\
\hline Honesty & 0.03 & 0.25 & 0.01 & 0.08 & 0.04 & 0.27 \\
\hline Target's gender & -0.04 & -0.39 & 0.09 & 0.77 & 0.07 & 0.57 \\
\hline Target's religiosity & & & -0.07 & -0.64 & 0.23 & $1.87+$ \\
\hline \multirow[t]{2}{*}{ Target's spirituality } & 0.24 & $2.65^{* *}$ & & & & \\
\hline & \multicolumn{2}{|c|}{$R^{2}=0.26$} & \multicolumn{2}{|c|}{$R^{2}=0.29$} & \multicolumn{2}{|c|}{$R^{2}=0.24$} \\
\hline
\end{tabular}

${ }^{*} p<0.05 .{ }^{* *} p<0.01 .{ }^{* * *} p<0.001 .{ }^{+} p<0.10$.

spirituality. As indicated by the correlational analysis, religion did not predict altruism in friend ratings. Interestingly, both self-reports and friend ratings also suggested the role of self-reported or perceived empathy on the target's self-reported or perceived altruism.

\section{General Discussion}

These four studies provide evidence that prosociality as a function of religiousness is certainly a limited but still substantial reality, in line with most psychological theories of religion. It is not a mere self-delusion of religious people, who are known to systematically perceive themselves as prosocial. Using projective measures allowing for spontaneous reactions where participants were unaware of the goal of the researchers, we found first that religious people (but not religious fundamentalists) tend not to respond in an aggressive manner when faced with hypothetical daily hassles (Study 1); and second, that religious women (there were no male participants) are liable to help an hypothetical family member or close person in need, but not necessarily an hypothetical unknown target in need (Study 2). Third, religious people not only tend to perceive themselves as behaving prosocially and, to some extent, as being empathetic and honest, but are also perceived as such by different kinds of peers (siblings, friends, and colleagues); this was confirmed with peers in three out of four cases (Studies 3 and 4). Fourth, social desirability (mainly impression management) seems to be a substantial personality characteristic rather than a self-presentation bias: the target's social desirability was related to his or her perception by a colleague as altruistic, and controlling for impression management did not have consequences on the relationship between religiousness and self-reported prosociality (Study 4). Finally, across the studies, there was evidence that the link of religiousness with prosociality is not an artifact of gender and gender differences in religion and prosociality constructs. This is an interesting finding since most previous empirical studies (both self-report based and experimental) on religion and prosocial traits and behavior did not control for the effects of gender.

Taken together, these studies suggest that it is difficult to accept the idea of moral hypocrisy in religious people regarding prosocial behavior. Such an idea could be hypothesized on the basis of an apparent contrast between self-reports and experimental studies documenting the importance of self-concern motivations in the prosociality of intrinsically religious people (Batson et al. 1993). If, however, we do not focus on the altruistic versus egotistic motivation issue, which is of course 
an important but partially independent question, these studies suggest that a certain prosociality accompanies religiousness, a quality that seems to be documented by sources of information other than self-report measures.

Of course, the impact of religion on prosociality, if we assume such a causal direction (but see Saroglou in press, for the opposite direction hypothesis), seems to be limited. First, it is perhaps limited to a "minimal" level of prosocial behavior, such as low aggression, and does not necessarily extend to high-cost prosocial actions. Social psychological experiments also indicate that the effect of religion on prosocial behavior is limited to low-cost actions (Batson, Schoenrade, and Ventis 1993).

Second, this effect is also limited, or more easily manifested, within the context of interpersonal relations with close persons with whom religious targets interact in everyday life and does not necessarily extend to a "universalistic love" of unknown targets. Data on 21 samples from 15 countries and many religious denominations (Saroglou, Delpierre, and Dernelle 2004) suggest that religiousness is positively associated with importance attributed to the value of benevolence (preservation and enhancement of the welfare of people with whom one is in frequent personal contact) but not with importance attributed to universalism (understanding, appreciation, tolerance, and protection of the welfare of all people and of nature). Extrapolating from the close-unknown to the ingroup-outgroup distinction, it seems that when the hypothetical targets appear as threatening values, religion even predicts low helping (Batson et al. 1999; Jackson and Esses 1997). More generally, the present findings are in line with the idea of religion as promoting an arena for delimited coalitions and alliances where extended reciprocal altruism and kin selection are present (Batson 1983; Kirkpatrick 1999b).

Third, the effect is also limited in its size: most of the significant results across our four studies reflect weak or moderate associations both in self-reports and peer ratings. Interestingly, two metaanalyses of studies on religion and the five factors of personality (in total: 8,282 participants) indicate a mean $r=0.20$ (Saroglou 2002a; eight studies) or 0.18 (Saroglou in press; another 14 studies), expressing the association between religiousness and agreeableness. This weak effect is not surprising. As argued elsewhere (Saroglou in press), if we follow the person-situation interaction debate (Funder 2001; Mischel 2004), it is to be expected that the size of the effect of religion on prosocial behavior varies importantly as a function of context. In Study 2, for instance, the association between religiosity and helping a close person was $r=0.38$, whereas the one between religiosity and helping an unknown person was -0.01 .

Other limitations of the religion-prosociality relation can be advanced. One of them may be the consideration of the target's personal responsibility. It is to be expected that the presence or absence of such responsibility could have an impact, negative or positive, on the prosocial reaction of religious persons. For instance, religious fundamentalists are not willing to help hypothetical unemployed single mothers or homosexuals since they consider them as being responsible for their situation (Jackson and Esses 1997). Several studies also indicate that religiosity is positively related to just-world beliefs, the latter being defined by the idea of a correspondence between what happens and what a person deserves (Lerner 1980). Interestingly, in Study 2, one of the hypothetical situations provided to participants presented a person (a sibling or a classmate) asking for help with homework although the person had been partying over the last few days. In this situation, willingness to help was unrelated to religiosity and spirituality.

What are the processes possibly explaining why religious people tend to be prosocial? We had hypothesized that religious people may be prosocial because they are empathetic (tend to understand other's views, share others' feelings, are affected by others' suffering) and/or because it is important for them to be fair, honest, and show respect for prosocial norms. However, in both Studies 3 and 4, first, the association between religiousness and honesty was not clear and systematic, and gender seemed to be a moderator of this association (it is also not certain that the honesty scale used was strictly equivalent to an integrity test and that this scale was the best way for 
measuring, for instance, what Batson et al. (2002) call principlism). Second, multiple regression analyses indicated that religion was a unique predictor of prosociality, both in self-reports and peer ratings, beyond the impact of - respectively, self-reported or peer-evaluated - empathetic concern, perspective taking, and honesty. Interestingly, personal distress, a construct that constitutes one kind of empathetic reaction and that was found to relate positively with empathy (Study 4) but to be a negative predictor of prosocial acts (Study 3), was unrelated to religion measures. Finally, in Study 2, evidence was provided that willingness to help close persons in hypothetical situations as a function of religiousness was not due to security in attachment to parents, at least not as this attachment was retrospectively reported. In conclusion, the question of the psychological processes explaining prosocial actions as a function of religiousness remains open.

Evidently, the question of the underlying psychological processes is not completely independent of the question about the specific religious dimension concerned (Batson, Schoenrade, and Ventis 1993). For instance, although our studies mainly focused on religiousness in general, some results regarding spirituality may be interesting: there is an ongoing debate on whether modern spirituality is followed by altruism and generativity in a similar fashion to religion, or whether it reflects an individualistic, self-centered dimension (e.g., Bellah et al. 1985; Dillon, Wink, and Fay 2003). We found that, similarly to religiosity, the importance of spirituality in life was related to helping close persons (Study 2) and to high scores on prosociality (altruism scales and/or empathetic concern) in both self-perception and peer evaluations (Studies 3 and 4). However, two other results seem to distinguish spirituality from religiosity in that the former has a broader prosocial scope. First, spiritual people acted in a prosocial way spontaneously when also faced with the needs of hypothetical unknown persons (Study 2). This result is in line with some recent evidence that spirituality, contrary to religiosity, reflects an extension of prosocial concerns from one's network of acquaintances (benevolence) to all people (universalism) (see Saroglou 2003, for review). Second, and perhaps in continuity with the first result, it was spirituality rather than religiosity that was positively associated, although not systematically, with self-perception as being high in perspective taking (Studies 3 and 4) and with a similar evaluation provided by a friend (Study 3).

Some important limitations of our studies should be emphasized. First, although our measures of prosociality (projective measures and peer ratings) go beyond a research tradition heavily based on self-report questionnaires, they are all still paper-and-pencil measures and can consequently only provide indirect evidence on the prosocial behavior of religious people in real life. Note also that with the exception of some experiments (see Batson, Schoenrade, and Ventis 1993), the more recent social psychological experiments on religion and prosocial behavior are usually based on paper-and-pencil measures of prosociality. There is thus a need to go further and to carry out real experimental studies in this domain where behavior is directly observed.

Second, the impact of religiousness is only indirectly assumed through associations of prosocial measures with individual differences in religiousness. It is thus also important to go further and test hypotheses on directions of the causality, where religion (or better, some aspects of it) can play the role of an independent variable in experimental manipulations. Third, peer ratings should still only be considered as indirect indicators of prosocial behavior. Between-judges agreement is a question partially independent from the question of the accuracy of the judgment and the latter can be established when behavioral measures are used (Funder and Colvin 1997). In addition, when one takes into account the fact that even judges who are not acquaintances can accurately evaluate a target's personality even after having observed them for only a few minutes (Funder and Colvin 1997), we may still wonder whether such a "produced" impression of prosociality is only a surface reality or points to deeper internal motivations for prosocial behavior as a function of faith and spirituality. Nevertheless, our studies, together with previous literature, at least suggest that religious people are not delusional or dishonest when they report agreeableness, helping, and other prosocial dispositions: others perceive them as altruists and 
they really tend to act in a prosocial way to some extent, with some people, and under some conditions.

\section{ACKNOWLEDGMENTS}

We thank Michael C. Ashton and three anonymous reviewers for their helpful comments and suggestions on an earlier version of the manuscript. This research was supported in part by a grant from the Université catholique de Louvain. Results of Studies 1 and 2 were presented at the One Hundred Years of Psychology and Religion Conference (May 2003, Amsterdam, the Netherlands). Results of Study 4 were presented at the 2003 International Association of Psychology of Religion Conference (August 2003, Glasgow, Scotland), and results of Study 3 were presented at the 12th European Conference on Personality (July 2004, Groningen, the Netherlands). Study 3 is a part of the master's thesis of the third author and Study 4 is a part of the doctoral thesis (under progress) of the second author.

\section{Notes}

1. We are aware of the importance of distinguishing between "prosociality" or "prosocial behavior," as referring to acting in a way that benefits others, and "altruism," as implying an unselfish, altruistic motivation and concern for others rather than a concern for self when acting prosocially. However, the commonly used scales for measuring prosociality are called "altruism" scales. In order to simplify the presentation of our study, especially in the Results sections, we use the terms "prosociality, prosocial" and "altruism, altruistic" interchangeably; we only refer to an unselfish motivation when we use the expression "altruistic motivation."

2. As a reviewer suggested, it is not unlikely that differences in ratings between judges may derive from different subsets of perceived behaviors. Indeed, some very recent research in personality is starting to focus on this issue (e.g., Vazire 2004). Nevertheless, since use of peer ratings of religious personality is rather new for developing very specific hypotheses according to the type of judge, our main goal in including a variety of judges in Studies 3 and 4 was simply to guarantee a more accurate perception by close peers of prosociality as a function of religiousness.

3. This clear distinction between impression management and self-deception regarding their links with religion is in line with findings of a previous study using the same measure (avoiding overlap between the two social desirability components) in three samples of young Belgians, i.e., native, Muslim, and other immigrants (Saroglou and Galand 2004; see also Gillings and Joseph 1996, for a study in the United Kingdom).

4. Self-deception (see Table 5) was positively correlated with personal distress (in both peers' ratings) and negatively related to honesty and perspective taking in colleague ratings, but since these realities were found to be unrelated to the target's religiousness-spirituality, no further analyses were carried out.

\section{REFERENCES}

Altemeyer, B. 1996. The authoritarian specter. Cambridge, MA: Harvard University Press.

Altemeyer, B. and B. Hunsberger. 1992. Authoritarianism, religious fundamentalism, quest, and prejudice. International Journal for the Psychology of Religion 2:113-33.

Ashton, M. C. and K. Lee. 2001. A theoretical basis for the major dimensions of personality. European Journal of Personality 15:327-53.

Ashton, M. C., K. Lee, M. Perugini, P. Szarota, R. E. De Vries, L. Di Blas, K. Boies, and B. De Raad. 2004. A six-factor structure of personality-descriptive adjectives: Solutions from psycholexical studies in seven languages. Journal of Personality and Social Psychology 86:356-66.

Batson, C. D. 1983. Sociobiology and the role of religion in promoting prosocial behavior. Journal of Personality and Social Psychology 45:1380-85.

Batson, C. D., N. Ahmad, D. A. Lishner, and J.-A. Tsang. 2002. Empathy and altruism. In Handbook of positive psychology, edited by C. R. Snyder and S. J. Lopez, pp. 485-98. New York: Oxford University Press.

Batson, C. D., S. H. Eidelman, S. L. Higley, and S. A. Russell. 2001. “And who is my neighbor?”: II. Quest religion as a source of universal compassion. Journal for the Scientific Study of Religion 40:39-50.

Batson, C. D., R. B. Floyd, J. M. Meyer, and A. L. Winner. 1999. "And who is my neighbor?": Intrinsic religion as a source of universal compassion. Journal for the Scientific Study of Religion 38:31-40.

Batson, C. D., P. Schoenrade, and W. L. Ventis. 1993. Religion and the individual: A social-psychological perspective. New York: Oxford University Press.

Beit-Hallahmi, B. and M. Argyle. 1997. The psychology of religious behaviour, belief and experience. London: Routledge.

Bellah, R., R. Madsen, W. Sullivan, A. Swidler, and S. Tipton. 1985. Habits of the heart: Individualism and commitment in American life. Berkeley, CA: University of California Press. 
Boies, K., T.-Y. Yoo, A. Ebacher, K. Lee, and M. C. Ashton. 2004. Psychometric properties of scores on the French and Korean versions of the HEXACO Personality Inventory. Educational and Psychological Measurement 64:992-1006.

Burnstein, E., C. Crandall, and S. Kitayama. 1994. Some neo-Darwinian rules for altruism: Weighing cues for inclusive fitness as a function of the biological importance of the decision. Journal of Personality and Social Psychology 67:773-89.

Clark, W. H. and C. M. Warner. 1955. The relation of church attendance to honesty and kindness in a small community. Religious Education 50:340-42.

Costa, P. T., Jr., A. Terracciano, and R. R. McCrae. 2001. Gender differences in personality traits across cultures: Robust and surprising findings. Journal of Personality and Social Psychology 81:322-31.

Davis, M. H. 1983. Measuring individual differences in empathy: Evidence for a multidimensional approach. Journal of Personality and Social Psychology 44:113-26.

Dillon, M., P. Wink, and K. Fay. 2003. Is spirituality determinant to generativity? Journal for the Scientific Study of Religion 42:427-42.

Dovidio, J. F. and L. A. Penner. 2002. Helping and altruism. In Blackwell handbook of social psychology: Interpersonal processes, edited by G. J. O. Fletcher and M. S. Clark, pp. 162-95. Malden, MA: Blackwell.

Downey, D. B. 2001. Number of siblings and intellectual development. American Psychologist 56:497-504.

Eberly, M. B. and R. Montemayor. 1998. Doing good deeds: An examination of adolescent prosocial behavior in the context of parent-adolescent relationships. Journal of Adolescent Research 13:403-32.

Eisenberg, N. and R. A. Fabes. 1998. Prosocial development. In Handbook of child psychology: Vol. 3. Social, emotional, and personality development, edited by W. Damon (series ed.) and N. Eisenberg (vol. ed.), 5th ed., pp. 701-78. New York: Wiley.

Erikson, E. H. 1963. Childhood and society, 2nd ed. New York: Norton.

Eysenck, M. W. 1998. Personality and the psychology of religion. Mental Health, Religion, and Culture 1:11-19.

Freud, S. [1913] 1919. Totem and taboo, translated by A. A. Brills. London: Routledge.

_ . [1927] 1961. The future of an illusion, translated by J. Strachey. New York: Norton.

Friedrichs, R. W. 1960. Alter versus ego: An exploratory assessment of altruism. American Sociological Review 25:495508 .

Funder, D. C. 2001. Personality. Annual Review of Psychology 52:197-221.

Funder, D. C. and C. R. Colvin. 1997. Congruence of others' and self-judgments of personality. In Handbook of personality psychology, edited by R. Hogan, J. Johnson, and S. Briggs, pp. 617-47. New York: Academic Press.

Geen, R. G. 1998. Aggression and antisocial behavior. In Handbook of social psychology, 2nd ed., edited by D. T. Gilbert, S. T. Fiske, and G. Lindzey, pp. 317-56. New York: McGraw-Hill.

Gillings, V. and S. Joseph. 1996. Religiosity and social desirability: Impression management and self-deceptive positivity. Personality and Individual Differences 21:1047-50.

Gleason, K. A., L. A. Jensen-Campbell, and D. S. Richardson. 2004. Agreeableness as a predictor of aggression in adolescence. Aggressive Behavior 30:43-61.

Goldfried, J. and M. Miner. 2002. Quest religion and the problem of limited compassion. Journal for the Scientific Study of Religion 41:685-95.

Granqvist, P. 2002. Attachment and religiosity in adolescence: Cross-sectional and longitudinal evaluations. Personality and Social Psychology Bulletin 28:260-70.

Granqvist, P. and B. Hagekull. 1999. Religiousness and perceived childhood attachment: Profiling socialized correspondence and emotional compensation. Journal for the Scientific Study of Religion 38:254-73.

Hazan, C. and P. R. Shaver. 1987. Romantic love conceptualized as an attachment process. Journal of Personality and Social Psychology 52:511-24.

Hills, P., L. J. Francis, M. Argyle, and C. J. Jackson. 2004. Primary personality trait correlates of religious practice and orientation. Personality and Individual Differences 36:61-73.

Iannotti, R. J., E. M. Cummings, B. Pierrehumbert, M. J. Milano, and C. Zahn-Waxler. 1992. Parental influences on prosocial behavior and empathy in early childhood. In Child rearing: Influence on prosocial and moral development, edited by J. M. A. M. Janssens and J. R. M. Gerris, pp. 77-100. Amsterdam: Swets and Zeitlinger.

Jackson, L. M. and V. M. Esses. 1997. Of scripture and ascription: The relation between religious fundamentalism and intergroup helping. Personality and Social Psychology Bulletin 23:893-906.

James, W. [1902] 1985. The varieties of religious experience: A study in human nature. Cambridge, MA: Harvard University Press.

Jones, H. B., Jr. 1997. The Protestant ethic: Weber's model and the empirical literature. Human Relations 50:757-78.

Katz, R. C., J. Santman, and P. Lonero. 1994. Findings of the revised morally debatable behaviors scale. Journal of Psychology 128:15-21.

Kirkpatrick, L. A. 1999a. Attachment and religious representations and behavior. In Handbook of attachment: Theory, research, and clinical applications, edited by J. Cassidy and P. R. Shaver, pp. 803-22. New York: Guilford Press. 1999b. Toward an evolutionary psychology of religion and personality. Journal of Personality 67:921-52.

Krueger, R. F., B. M. Hicks, and M. McGue. 2001. Altruism and antisocial behaviour: Independent tendencies, unique personality correlates, distinct etiologies. Psychological Science 12:397-402. 
Laursen, B., L. Pulkkinen, and A. Ryan. 2002. The antecedents and correlates of agreeableness in adulthood. Developmental Psychology 38:591-603.

Laythe, B., D. Finkel, R. Bringle, and L. A. Kirkpatrick. 2002. Religious fundamentalism as a predictor of prejudice: A two-component model. Journal for the Scientific Study of Religion 41:623-35.

Lee, K. and M. C. Ashton. 2004. Psychometric properties of the HEXACO Personality Inventory. Multivariate Behavioral Research 39:329-58.

Lerner, M. J. 1980. The belief in a just world. New York: Plenum Press.

Lewis, C. A. 1999. Is the relationship between religiosity and personality "contaminated" by social desirability as assessed by the Lie Scale?: A methodological reply to Michael W. Eysenck (1998). Mental Health, Religion and Culture 2:105-14.

2000. The religiosity-psychoticism relationship and the two factors of social desirability: A response to Michael W. Eysenck (1999). Mental Health, Religion and Culture 3:39-45.

Luyten, P., J. Corveleyn, and J. R. J. Fontaine. 1998. The relationship between religiosity and mental health: Distinguishing between shame and guilt. Mental Health, Religion, and Culture 1:165-84.

Mahoney, A., K. I. Pargament, T. Jewell, A. B. Swank, E. Scott, R. Emery, and M. Rye. 1999. Marriage and the spiritual realm: The role of proximal and distal religious constructs in marital functioning. Journal of Family Psychology 13:321-38.

Martin, R., D. Watson, and C. K. Wan. 2000. A three-factor model of trait anger: Dimensions of affect, behavior, and cognition. Journal of Personality 68:869-97.

McCullough, M. E., J.-A. Tsang, and S. Brion. 2003. Personality traits in adolescence as predictors of religiousness in early adulthood: Findings from the Terman Longitudinal Study. Personality and Social Psychology Bulletin 29:980-91.

McCullough, M. E. and E. L. Worthington, Jr. 1999. Religion and the forgiving personality. Journal of Personality 67:1141-64.

McFadden, S. H. 1999. Religion, personality, and aging: A life span perspective. Journal of Personality 67:1081-1104.

Mikulincer, M., O. Gillath, V. Halevy, N. Avihou, S. Avidan, and N. Eshkoli. 2001. Attachment theory and reactions to others' needs: Evidence that activation of the sense of attachment security promotes empathic responses. Journal of Personality and Social Psychology 81:1205-24.

Mischel, W. 2004. Toward an integrative science of the person. Annual Review of Psychology 55:1-22.

Ones, D. S., C. Viswesvaran, and A. D. Reiss. 1996. Role of social desirability in personality testing for personnel selection: The red herring. Journal of Applied Psychology 81:660-79.

Paulhus, D. 1991. Measurement and control of response bias. In Measures of personality and social psychological attitudes, edited by J. Robinson, P. Shaver, and L. Wrightsman, pp. 17-59. New York: Academic Press.

Piedmont, R. L., R. R. McCrae, R. Riemann, and A. Angleitner. 2000. On the invalidity of validity scales: Evidence from self-reports and observer ratings in volunteer samples. Journal of Personality and Social Psychology 78:582-93.

Rosenzweig, S. 1948. The Rosenzweig picture frustration study: Revised form for adults. St. Louis, MO: Author.

- 1976. Aggressive behavior and the Rosenzweig picture-frustration (P-F) study. Journal of Clinical Psychology 32:885-91.

Rushton, J. P., R. D. Chrisjohn, and G. C. Fekken. 1981. The altruistic personality and the Self-Report Altruism Scale. Personality and Individual Differences 2:293-302.

Saroglou, V. 2001. Paternity as function: Structuring the religious experience, translated by S. Allen. Amsterdam, Atlanta: Rodopi.

2002a. Religion and the five factors of personality: A meta-analytic review. Personality and Individual Differences 32:15-25.

2002b. Religiousness, religious fundamentalism, and quest as predictors of humor creation. International Journal for the Psychology of Religion 12:177-88.

- 2003. Spiritualité moderne: Un regard de psychologie de la religion [Modern spirituality: A psychology of religion view]. Revue Théologique de Louvain 34:473-504.

- In press. Personality and religion: A big five factor perspective. In Handbook of psychology of religion, edited by D. Wulff. New York: Oxford University Press.

Saroglou, V., V. Delpierre, and R. Dernelle. 2004. Values and religiosity: A meta-analysis of studies using Schwartz's model. Personality and Individual Differences 37:721-34.

Saroglou, V. and L. Fiasse. 2003. Birth order, personality, and religion: A study among young adults from a three-sibling family. Personality and Individual Differences 35:19-29.

Saroglou, V. and P. Galand. 2004. Identities, values, and religion: A study among Muslim, other immigrant, and native Belgian young adults after the 9/11 attacks. Identity: An International Journal of Theory and Research 4:97132.

Saroglou, V. and J.-M. Jaspard. 2001. Does religion affect humour creation? An experimental study. Mental Health, Religion, and Culture 4:33-46.

Schieman, S. and K. Van Gundy. 2000. The personal and social links between age and self-reported empathy. Social Psychological Quarterly 63:152-74.

Skinner, B. F. 1969. Contingencies of reinforcement: A theoretical analysis. New York: Appleton-Century-Crofts. 
Spilka, B., R. W. Hood, Jr., B. Hunsberger, and R. Gorsuch. 2003. The psychology of religion: An empirical approach, 3rd ed. New York: Guilford Press.

Storch, E. A. and J. B. Storch. 2002. Intrinsic religiosity and aggression in a sample of intercollegiate athletes. Psychological Reports 91:1041-42.

Tournois, J., F. Mesnil, and J.-L. Kop. 2000. Self-deception and other-deception: A social desirability questionnaire. European Review of Applied Psychology 50:219-33.

van der Mark, I. L., M. H. van IJzendoorn, and M. J. Bakermans-Kranenburg. 2002. Development of empathy in girls during the second year of life: Associations with parenting, attachment, and temperament. Social Development $11: 451-68$.

Vazire, S. 2004. Immaculate perceptions? Why and how to go beyond self-reports in personality assessment. Paper presented at the 12th European Conference on Personality, Groningen, the Netherlands. 